\title{
Marginalization and Its Association with Dental Caries among 5-12 Years Old Slum Children in Central India
}

\section{Singh $\mathrm{A}^{1 *}$, Raushan $\mathrm{SK}^{2}$ and Purohit $\mathrm{BM}^{3}$}

${ }^{1}$ Department of Dentistry, All India Institute of Medical

Sciences (AIIMS), India

${ }^{2}$ Medical Student, All India Institute of Medical Sciences (AIIMS), India

${ }^{3}$ Department of Public Health Dentistry, People's College of Dental Sciences, India

*Correspondling author: Singh A, Department of Dentistry, All India Institute of Medical Sciences (AIIMS), Bhopal, India

Received: November 03, 2016; Accepted: J anuary 25, 2017; Published: J anuary 31, 2017

\section{Abstract}

Objective: The aim of the study was to assess dental caries and associated risk factors among 5-12 year old slum dwelling children in Bhopal City, Central India.

Methods: A total of 311 children were there in the 5-12 year old age group and all were examined. Information on demographic characteristics of participants along with parent's literacy status, annual family income, oral health behaviors and visits to health personnel for dental needs were collected. Data was collected on dental caries of primary dentition (dmft) and permanent dentition (DMFT) using modified WHO criteria (1997). Linear and logistic regression analysis was performed to determine the factors associated with dmft/DMFT status. Odds ratio was calculated for all variables with $95 \%$ confidence intervals.

Results: Ninety three $(26.7 \%)$ and sixty $(19.3 \%)$ children were having one or more decayed teeth (dt/DT) in primary and permanent dentition respectively. Mean dmft/DMFT scores were $0.69 \pm 1.42$ and $0.35 \pm 0.90$ in the primary and permanent dentition respectively. Variables in the dmft/DMFT model explained only $18.3 \%$ and $8 \%$ of the variance in the primary and permanent dentition.

Conclusion: The study reveals exceptionally low dental care utilization and dental caries levels among slum dwelling children. Addressing marginalization will require a responsive and a caring workforce on the part of health authorities and government. slum

Keywords: Caries risk; Childhood caries; Disadvantaged children; Urban

live in slums and the figure will likely grow to 2 billion by 2030 [4]. Populations report estimated urban slum population in India as approximately 70 million by mid 2011 [5]. Even more disturbing is a truth that urban poverty is underestimated as many of the urban poor live in undocumented squatter colonies and pavements.

In India children comprise $40 \%$ of a rapidly growing population. Approximately, $26.3 \%$ of the urban population resides in urban slums.5 Squalor, lack of clean drinking water, unhygienic sanitary environment, crowding and garbage disposal pose series of threats to the health of slum dwellers children in particular, as they spend most of their time around the unhygienic environment. Infant mortality rates are twice as high in slums as the national rural average. Nutritional problems like Protein Energy Malnutrition (PEM), anemia and vitamin A deficiency continue to plague a large proportion of Indian children. The nutritional status of slum children is worst amongst all urban groups and is even poorer than the rural average. On average, slum children are more nutritionally wasted than other children. Lack of education and information further aggravates the situation as residents depend on unreliable sources for prevention and cure [6].

These children are imperative to the nation's present and its future. Yet populations vary considerably in their obligation to the collective health of children and in the resources that they make available to meet children's needs. This is reflected in the ways in which society address their shared commitment to children's health. 
It is suggested that marginalized populations have grave and pessimistic views of health in general including oral health [7]. According to World Oral Health Report 2003, National Oral Health Survey 2003 and a number of point prevalence studies a fact appears that dental caries is increasing both in prevalence and severity over the last few decades in developing countries [8-10]. Dental caries is a major public health problem owing to their high prevalence and incidence globally, specifically among children. Unfortunately, no published study has investigated the prevalence of dental caries globally among slum children making it difficult to understand the pattern of oral health status in this marginalized community. Also, there is no data on the oral health status of children residing in slums in India. Therefore, this study explores the association between this marginalized group and oral health. Specifically, the aim of the study was to assess dental caries status and associated risk factors among 5-12 year old slum dwelling children in Bhopal City, Central India.

\section{Materials and Methods}

\section{Study design and subjects}

The target population for the cross-sectional study was 5-12 year old children in an urban slum area in Bhopal City, Central India. All households were visited and the children aged 5-12 years were invited to participate in the study. If the house was locked or child not present at time of visit then a second visit was arranged to include the children in that particular house. A total of 311 children were there in 5-12 year old age group and all were examined.

Information on demographic characteristics of participants along with parents literacy status, annual family income, oral health behaviors such as frequency of brushing, material used for cleaning teeth, and visits to any health personnel for dental needs were collected by means of personal interviews administered by the examiner. Age was sub classified in 3 groups namely 5-6 years, $7-10$ years and 1112 years. Paternal and maternal literacy levels were categorized for study subjects. The four categories recorded were illiterate (no formal education), completed middle school ( $6^{\text {th }}$ Grade), completed high school $\left(12^{\text {th }}\right.$ Grade) and those with a graduation or higher degree. Similarly, family income levels were recorded as $\leq 60,000$, earning between Rs 60,000 - Rs 120,000 ( 1000 to 2000 US \$) and those earning $\geq 120,000$ ( $\sim 2000$ US \$). The dental team comprised of the examiner assisted by a recording clerk.

\section{Clinical examination}

All the subjects were examined under adequate illumination and clinical data were collected on dental caries of primary dentition (dmft) and permanent dentition (DMFT) using modified WHO criteria (1997) [11]. The examination was conducted with a plane mouth mirror. A systematic approach was adopted for assessment of dental caries. The examination proceeded in an orderly manner from one tooth or tooth space to the adjacent tooth or tooth space. A tooth was considered present in mouth when any part of it was visible.

Subjects were examined seated in a chair, with the examiner standing approximately in 10 o' clock position, under natural daylight. The subject well positioned so as to receive maximum illumination, while avoiding discomfort from direct sunlight. The recorder was made to sit close enough so that instructions could be easily heard and the examiner could see that the findings were being recorded
Table 1: Distribution of subjects according to age, gender, parent's literacy and income status.

\begin{tabular}{|c|c|c|c|}
\hline \multirow[b]{2}{*}{ Age group (years) } & \multicolumn{2}{|c|}{ Gender } & \multirow{2}{*}{$P$ value } \\
\hline & Male (\%) & Female $(\%)$ & \\
\hline $5-6$ years & $37(24)$ & $41(26.1)$ & \multirow{3}{*}{0.571} \\
\hline $7-10$ years & $76(49.4)$ & $78(49.7)$ & \\
\hline 11-12 years & $41(26.6)$ & $38(24.2)$ & \\
\hline Total & $154(100)$ & $157(100)$ & $311(100)$ \\
\hline Literacy status & Father $(\%)$ & Mother (\%) & $P$ value \\
\hline Illiterate & $70(22.5)$ & $117(37.6)$ & \multirow{5}{*}{0.001} \\
\hline Completed middle school (6 $6^{\text {th }}$ Grade) & $37(11.9)$ & $66(21.2)$ & \\
\hline Completed high school ( $12^{\text {th }}$ Grade) & $188(60.5)$ & $116(37.3)$ & \\
\hline Graduation and higher & $16(5.1)$ & $12(3.9)$ & \\
\hline Total & $311(100)$ & $311(100)$ & \\
\hline Annual Family Income levels (Rs)* & Male (\%) & Female $(\%)$ & $P$ value \\
\hline$\leq 60,000$ & $96(62.4)$ & $84(53.5)$ & \multirow{4}{*}{0.062} \\
\hline $\begin{array}{c}\geq 60,000 \leq 120,000(\sim 1000 \text { to } 2000 \\
\text { US } \$)\end{array}$ & $53(34.4)$ & $62(39.5)$ & \\
\hline$\geq 120,000(\sim 2000$ US $\$)$ & 05 ( 3.2$)$ & $11(7)$ & \\
\hline Total & $154(100)$ & $157(100)$ & \\
\hline
\end{tabular}

*1US \$ = 61.60 Indian Rupees.

correctly. Oral examination was conducted by a single examiner and was done in uniform manner beginning from the maxillary right quadrant in a clockwise direction in maxillary and mandibular region

Ethical clearance was taken from Institutional Ethics Committee, All India Institute of Medical Sciences (AIIMS), Bhopal, Central India. Research had been conducted in full accordance with the World Medical Association Declaration of Helsinki. Informed written consent was taken from parents and children prior to conducting the survey. The survey was scheduled between the months of July 2014 and September 2014. Training and calibration of examiner was conducted in Department of Dentistry, AIIMS, Bhopal. A pilot study was conducted on 30 children each to see the feasibility of study. All examinations were performed by a single examiner and duplicate examinations were conducted on one of every ten subjects throughout the survey. Intra- examiner reliability for indices was assessed using kappa statistic which was in range of $0.92-0.94$.

\section{Statistical analysis}

Data was collected, entered and analyzed using SPSS version 16.0 (SPSS Inc., Chicago, Illinois, USA) for windows. Mean and standard deviations were used as basic descriptive statistics. Chi Square test was used to compare between categorical variables. Mann - Whitney U-test was used for comparison between two groups for quantitative variables. Analysis of Variance (ANOVA) was used to compare the mean $\mathrm{dmft} / \mathrm{DMFT}$ scores among the three age groups. Linear and logistic regression analysis was performed to determine the factors associated with $\mathrm{dmft} / \mathrm{DMFT}$ status. A set of independent variables including age, gender, parent's education, annual family income, frequency of cleaning teeth, frequency of between meal sugar consumption (previous day) and utilization of dental care was considered in the regression model. Odds ratio was calculated for all variables with $95 \%$ confidence intervals. All the dependent variables to be included in the regression analysis were dichotomized. 
Table 2: Oral health behavioural characteristics among study subjects.

\begin{tabular}{|c|c|c|c|c|c|}
\hline \multirow{2}{*}{\multicolumn{2}{|c|}{ Oral health related behaviour variables }} & \multicolumn{2}{|c|}{ Gender } & \multirow{3}{*}{$P$ value } & \multirow{3}{*}{$\begin{array}{c}\text { Total (\%) } \\
9(2.9)\end{array}$} \\
\hline & & \multirow{2}{*}{\begin{tabular}{|c|} 
Male (\%) \\
$3(1.9)$
\end{tabular}} & \multirow{2}{*}{$\begin{array}{c}\text { Female (\%) } \\
6(3.8)\end{array}$} & & \\
\hline \multirow{2}{*}{ Mode of cleaning teeth } & Finger & & & & \\
\hline & Toothbrush & $151(98.1)$ & $151(96.2)$ & 0.324 & $302(97.1)$ \\
\hline \multirow{2}{*}{ Frequency of cleaning teeth } & Once daily & $143(92.8)$ & $141(89.8)$ & & $284(91.3)$ \\
\hline & $\geq 2$ times a day & $11(7.2)$ & $15(10.2)$ & 0.449 & $26(8.7)$ \\
\hline \multirow{2}{*}{ Material used for cleaning teeth } & Toothpaste & $145(95.2)$ & $151(96.1)$ & & $296(95.1)$ \\
\hline & Toothpowder & $9(4.8)$ & $6(4.9)$ & 0.405 & $15(4.9)$ \\
\hline \multirow{2}{*}{ Dietary Habits } & Vegetarian diet & $90(58.4)$ & $78(49.6)$ & & $168(54)$ \\
\hline & Mixed diet & $64(51.6)$ & $79(50.4)$ & 0.121 & $143(46)$ \\
\hline \multirow{3}{*}{ Frequency of between meal sugar consumption the previous day } & Once a day & $74(48.1)$ & $88(56.1)$ & & $162(52)$ \\
\hline & Two times a day & $40(25.9)$ & $27(17.2)$ & 0.081 & $67(21.5)$ \\
\hline & $\geq$ Thrice daily & $40(26)$ & $42(26.7)$ & & $82(26.5)$ \\
\hline \multirow{2}{*}{ Utilization of dental care } & Never visited & $145(94.2)$ & $146(93)$ & & $291(93.6)$ \\
\hline & Visited once in last one year & $9(5.8)$ & $11(7)$ & 0.945 & $20(6.4)$ \\
\hline \multirow{2}{*}{ Reason for visit } & Routine check up & 0 & 0 & & 0 \\
\hline & Pain with teeth/gums & $9(5.8)$ & $11(7)$ & 0.172 & $20(6.4)$ \\
\hline
\end{tabular}

Table 3: Dental caries status among study subjects.

\begin{tabular}{|c|c|c|c|c|c|}
\hline \multicolumn{2}{|c|}{ Clinical variables } & \multirow{2}{*}{\begin{tabular}{|l|} 
Male N (\%) \\
$108(70.1)$ \\
\end{tabular}} & \multirow{2}{*}{\begin{tabular}{|c|} 
Female N (\%) \\
$110(70)$
\end{tabular}} & \multirow{3}{*}{\begin{tabular}{|c|}
$\mathbf{P}$ \\
Value \\
0.85 \\
\end{tabular}} & \multirow{2}{*}{$\begin{array}{l}\text { Total (\%) } \\
228(73.3)\end{array}$} \\
\hline \multirow{2}{*}{$\begin{array}{l}\text { decayed teeth (dt) } \\
\text { N (\%) }\end{array}$} & Absent & & & & \\
\hline & Present & $46(29.9)$ & $47(30)$ & & $93(26.7)$ \\
\hline \multirow{2}{*}{$\begin{array}{l}\text { missing teeth }(\mathrm{mt}) \\
\mathrm{N}(\%)\end{array}$} & Absent & $150(97.4)$ & $154(98.1)$ & \multirow{2}{*}{0.83} & 304 (97.7) \\
\hline & Present & $04(2.6)$ & $03(1.9)$ & & $07(2.3)$ \\
\hline \multirow{2}{*}{$\begin{array}{l}\text { filled teeth (ft) } \\
N(\%)\end{array}$} & Absent & $154(100)$ & $156(99.4)$ & \multirow{2}{*}{0.32} & $310(99.7)$ \\
\hline & Present & $0(0)$ & $01(0.6)$ & & $01(0.3)$ \\
\hline \multicolumn{2}{|l|}{ Mean dmft } & $0.64 \pm 1.21$ & $0.73 \pm 1.60$ & 0.37 & $0.69 \pm 1.42$ \\
\hline \multirow{3}{*}{$\begin{array}{l}\text { Range dmft } \\
\text { N (\%) }\end{array}$} & 0 & $107(69.4)$ & $107(68.1)$ & \multirow{3}{*}{063} & $214(68.8)$ \\
\hline & $1-3$ & $42(27.2)$ & $43(27.4)$ & & $85(27.3)$ \\
\hline & $>3$ & $5(3.2)$ & $7(4.5)$ & & $12(3.86)$ \\
\hline \multirow{2}{*}{$\begin{array}{l}\text { Decayed teeth } \\
\text { (DT) } \\
\mathrm{N}(\%)\end{array}$} & Absent & $117(76)$ & $134(85.3)$ & \multirow{2}{*}{0.21} & $251(80.7)$ \\
\hline & Present & $37(24)$ & $23(14.7)$ & & $60(19.3)$ \\
\hline \multirow{2}{*}{$\begin{array}{l}\text { Missing teeth (MT) } \\
\mathrm{N}(\%)\end{array}$} & Absent & $154(100)$ & $157(100)$ & \multirow{2}{*}{0.28} & $311(100)$ \\
\hline & Present & $0(0)$ & (0) & & $0(0)$ \\
\hline \multirow{2}{*}{$\begin{array}{l}\text { Filled teeth (FT) } \\
\mathrm{N}(\%)\end{array}$} & Absent & $153(99.4)$ & $157(100)$ & \multirow{2}{*}{0.31} & $310(99.7)$ \\
\hline & Present & $1(0.6)$ & $0(0)$ & & $1(0.3)$ \\
\hline \multicolumn{2}{|l|}{ Mean DMFT } & $0.40 \pm 0.85$ & $0.31 \pm 0.94$ & 0.037 & $0.35 \pm 0.90$ \\
\hline \multirow{3}{*}{$\begin{array}{l}\text { Range DMFT } \\
\mathrm{N}(\%)\end{array}$} & 0 & $116(75.3)$ & $133(84.7)$ & \multirow{3}{*}{0.05} & $249(80)$ \\
\hline & $1-3$ & $36(23.3)$ & $22(14)$ & & $58(18.6)$ \\
\hline & $>3$ & $2(1.3)$ & $2(1.3)$ & & $4(1.28)$ \\
\hline
\end{tabular}

Significance was fixed at $\mathrm{p}$ value of $\leq 0.05$.

\section{Results}

A total of 311 children comprised the sample, of them 154 (49.5\%) were males and 157 (50.5\%) were females. No Significant gender differences were noted between the two groups. Also, no significant gender differences were noted among the three age groups of 5-6 years, 7-10 years and 11-12 years. Only, 16 (5.1\%) of the paternal study population and $12(3.9 \%)$ of the maternal population had a graduation or higher level of education. Higher levels of illiteracy, $70(37.6 \%)$ were noted among the mothers, in contrast to their counterparts 117 (22.5\%). Significant differences were noted between parental levels of education for the study subjects ( $\mathrm{p} \leq 0.001)$. No gender differences were noted between annual family incomes for study population (Table 1).

Toothbrush was used by $302(97.1 \%)$ children. Toothpaste was the most common method used for cleaning teeth among 296 (95.1\%) children. Only, 26 (8.7\%) of the children brushed their teeth two or more times a day. Sugar consumption three or more times the previous day was noted among $82(26.5 \%)$ children. Also, only $20(6.4 \%)$ children had visited the dentist and the single associated reason being the pain of teeth or gums. None of the children had taken a routine dental check up. No gender differences were noted for frequency of cleaning teeth, material used for cleaning teeth, type of diet, previous day sugar consumption, utilization for dental care and reason for dental visit (Table 2).

Ninety three (26.7\%) children from the study group were having one or more decayed teeth. Only, one (.6\%) girl child had filled teeth ( $\mathrm{ft}$ ) in the primary dentition. Mean dmft scores in the primary dentition being $0.69 \pm 1.42$. Two hundred fourteen $(68.8 \%), 85$ (27.3\%) and 12 (3.8\%) children had a dmft score in range of 0, 1-3 and $>3$. in the primary dentition. No significant gender differences were noted for decayed teeth $(\mathrm{dt})$, missing teeth $(\mathrm{mt})$, filled teeth $(\mathrm{ft})$, mean dmft scores and dmft range. Sixty children (19.3\%) children had Dental Caries (DT) in the permanent dentition. None of the children had Missing Teeth (MT) in the permanent dentition. Again, only 1 (.3\%) male child had Filled Teeth (FT) in the permanent dentition. Mean DMFT score for the study population was $0.35 \pm 0.90$. Also, 
Table 4: Distribution of dental caries according to age and gender.

\begin{tabular}{|c|c|c|c|c|}
\hline \multirow{2}{*}{ Age Group } & \multicolumn{2}{|c|}{ Dental Caries (dt) } & \multirow{2}{*}{$P$ value } & \multirow{2}{*}{ Total N (\%) } \\
\hline & Male N (\%) & Female N (\%) & & \\
\hline 5-6 years & $7(4.5)$ & $11(7)$ & \multirow{3}{*}{0.001} & $18(5.7)$ \\
\hline 7-10 years & $34(22)$ & $32(20.3)$ & & $66(21.2)$ \\
\hline $11-12$ years & $5(3.2)$ & $4(2.5)$ & & $9(2.9)$ \\
\hline \multirow{2}{*}{ Age Group } & \multicolumn{2}{|c|}{ Dental Caries (DT) } & \multirow{2}{*}{$P$ value } & \multirow[b]{2}{*}{ Total N (\%) } \\
\hline & Male N (\%) & Female $\mathrm{N}(\%)$ & & \\
\hline 5-6 years & $0(0)$ & $0(0)$ & \multirow{3}{*}{0.001} & $0(0)$ \\
\hline 7-10 years & $20(13)$ & $15(9.5)$ & & $35(11.2)$ \\
\hline 11-12 years & $17(11)$ & $8(5)$ & & $25(8)$ \\
\hline \multirow{2}{*}{ Age Group } & \multicolumn{2}{|c|}{ Mean dmft } & \multirow{2}{*}{$P$ value } & \multirow[b]{2}{*}{ Mean dmft } \\
\hline & Male & Female & & \\
\hline 5-6 years & $0.72 \pm 1.53$ & $0.78 \pm 1.75$ & \multirow{3}{*}{0.001} & $0.75 \pm 1.64$ \\
\hline 7-10 years & $0.82 \pm 1.22$ & $0.97 \pm 1.81$ & & $0.90 \pm 1.54$ \\
\hline $11-12$ years & $0.21 \pm 0.65$ & $0.21 \pm 0.57$ & & $0.21 \pm 0.61$ \\
\hline \multirow{2}{*}{ Age Group } & \multicolumn{2}{|c|}{ Mean DMFT } & \multirow{2}{*}{$P$ value } & \multirow[b]{2}{*}{ Mean DMFT } \\
\hline & Male & Female & & \\
\hline 5-6 years & $0.00 \pm 0.00$ & $0.00 \pm 0.00$ & \multirow{3}{*}{0.001} & $0.00 \pm 0.00$ \\
\hline 7-10 years & $0.44 \pm 0.87$ & $0.39 \pm 0.90$ & & $0.42 \pm 0.88$ \\
\hline 11-12 years & $0.68 \pm 1.05$ & $0.47 \pm 1.38 .00$ & & $0.58 \pm 1.22$ \\
\hline
\end{tabular}

no significant gender differences were noted for DT, MT, FT and mean DMFT values. Two hundred forty nine (80\%), 58 (18.6\%) and $4(1.2 \%)$ children had DMFT score of $0,1-3$ and $>3$, differences noted being significant for gender $(\mathrm{p} \leq 0.05)$ (Table 3 ).

In primary dentition 18 (5.7\%), $66(21.2)$ and $9(2.9 \%)$ of the children had dental caries in the three respective age groups of 5-6 years, 7-10 years and $11-12$ years $(\mathrm{p} \leq 0.001)$. Similarly, significant differences in the permanent dentition were noted among 0 (0), 35 (11.2\%) and $25(8 \%)$ children for Dental Caries (DT) in the three age groups $(\mathrm{p} \leq 0.001)$. Mean $\mathrm{dmft}$ scores for the 5-6 years, 7-10 years and 11 to 12 years age groups in primary dentition were $0.75 \pm 1.64$, $0.90 \pm 1.54$ and $0.21 \pm 0.61$ respectively. Mean DMFT scores for the permanent dentition being $0.00 \pm 0.00,0.42 \pm 0.88$ and $0.58 \pm 1.22$ for the respective age groups. Significant differences were found for primary and permanent dentition ( $\mathrm{dmft} / \mathrm{DMFT}$ ) between the three age groups of 5-6 years, 7-10 years and 11 to 12 years $(\mathrm{p} \leq 0.001)$ (Table 4).

Table 5 depicts the stepwise multiple linear regression analysis for the dmft (primary dentition) and DMFT (permanent dentition) scores in relation to several independent variables, which includes age, gender, paternal education, maternal education, annual family income, frequency of cleaning teeth, sugar consumption (previous day) and utilization of dental care. Variables in the model explained only $18.3 \%$ of the variance in $\mathrm{dmft}$ status for the primary dentition. Increasing age, higher in between meal sugar consumption and lower utilization of dental care attributed for $2.4 \%, 5.7 \%$ and $8.8 \%$ of the $\mathrm{dmft}$ scores $(\mathrm{p} \leq 0.001)$. Similarly, only $8 \%$ of the variance was explained by all the variables for the DMFT scores in the permanent dentition. Increasing age contributed $5.6 \%$ and lower levels of
Table 5: Multiple Linear Regression model for dmft (Primary dentition) and DMFT (Permanent Dentition).

\begin{tabular}{|c|c|c|c|c|c|c|}
\hline \multicolumn{7}{|c|}{ Multiple Linear Regression model for $\mathrm{dmft}$} \\
\hline Model & $\mathrm{R}$ & $\mathrm{R}^{2}$ & Adjusted $\mathrm{R}^{2}$ & SE & $\mathrm{R}^{2}$ Change & $\mathrm{P}$ \\
\hline 1 & $0.15^{a}$ & 0.024 & 0.021 & 1.41 & 0.024 & 0.001 \\
\hline 2 & $0.157^{\mathrm{b}}$ & 0.025 & 0.018 & 1.41 & 0.001 & 0.021 \\
\hline 3 & $0.165^{c}$ & 0.027 & 0.018 & 1.41 & 0.002 & 0.07 \\
\hline 4 & $0.170^{\mathrm{d}}$ & 0.029 & 0.016 & 1.41 & 0.002 & 0.36 \\
\hline 5 & $0.171^{\mathrm{e}}$ & 0.029 & 0.013 & 1.41 & 0.00 & 0.107 \\
\hline 6 & $0.194^{f}$ & 0.038 & 0.019 & 1.41 & 0.009 & 0.069 \\
\hline 7 & $0.308^{g}$ & 0.095 & 0.074 & 1.37 & 0.057 & 0.001 \\
\hline 8 & $0.428^{\mathrm{h}}$ & 0.183 & 0.161 & 1.30 & 0.088 & 0.001 \\
\hline \multicolumn{7}{|c|}{ Multiple Linear Regression model for DMFT } \\
\hline Model & $\mathrm{R}$ & $\mathrm{R}^{2}$ & Adjusted $\mathrm{R}^{2}$ & SE & $\mathrm{R}^{2}$ Change & $\mathrm{P}$ \\
\hline 1 & $0.236^{\mathrm{a}}$ & 0.056 & 0.053 & 0.87 & 0.056 & 0.001 \\
\hline 2 & $0.239^{b}$ & 0.057 & 0.051 & 0.88 & 0.001 & 0.58 \\
\hline 3 & $0.272^{\mathrm{c}}$ & 0.074 & 0.065 & 0.87 & 0.017 & 0.001 \\
\hline 4 & $0.272^{\mathrm{d}}$ & 0.074 & 0.062 & 0.87 & 0.00 & 0.27 \\
\hline 5 & $0.28^{\mathrm{e}}$ & 0.077 & 0.062 & 0.87 & 0.003 & 0.34 \\
\hline 6 & $0.277^{f}$ & 0.077 & 0.059 & 0.87 & 0.00 & 0.38 \\
\hline 7 & $0.279^{g}$ & 0.078 & 0.056 & 0.87 & 0.001 & 0.43 \\
\hline 8 & $0.283^{h}$ & 0.080 & 0.055 & 0.87 & 0.002 & 0.47 \\
\hline
\end{tabular}

a. Predictors: Age,

b. Predictors: Age, Gender

c. Predictors: Age, Gender, Paternal education

d. Predictors: Age, Gender, Paternal Education, Maternal education

e. Predictors: Age, Gender, Paternal Education, Maternal Education, Annual Family Income,

f. Predictors: Age, Gender, Paternal Education, Maternal Education, Annual Family Income, Frequency of cleaning teeth

g. Predictors: Age, Gender, Paternal Education, Maternal Education, Annual Family Income, Frequency of cleaning teeth Fathers, Sugar consumption (previous day)

h. Predictors: Age, Gender, Paternal Education, Paternal Education, Annual Family Income, Frequency of cleaning teeth, Sugar consumption (previous day), Utilization of dental care

paternal education attributed $1.7 \%$ to the DMFT scores in the present study $(\mathrm{p} \leq 0.001)$.

Logistic regression analysis was employed to determine the contribution of age, gender, paternal education, maternal education, annual family income, frequency of cleaning teeth, sugar consumption (previous day) and utilization of dental care towards dmft/DMFT status. The results of logistic regression showed that age, previous day sugar consumption and utilization of dental care were significantly related to $\mathrm{dmft}$ scores. Children aged nine and above were more likely to have higher $\mathrm{dmft}$ score than the 5 to 8 years old $(\mathrm{OR}=1.62$; $\mathrm{P} \leq$ $0.001)$. High frequency of between meal sugar consumption was also related to higher $\mathrm{dmft}$ sores $(\mathrm{OR}=2.68 ; \mathrm{P} \leq 0.001)$. Low utilization of dental care was associated with higher $\mathrm{dmft}$ scores $(\mathrm{OR}=2.68$; $\mathrm{P} \leq 0.001)$. In the permanent dentition among the variables only increasing age was significantly associated to DMFT scores (OR = $4.3 ; \mathrm{P} \leq 0.001$ ) (Table 6).

\section{Discussion}

Equity is an ethical concept grounded in the principle of 
Table 6: Risk factors associated with dmft (Primary dentition) and DMFT (Permanent dentition).

\begin{tabular}{|c|c|c|c|}
\hline \multicolumn{5}{|c|}{ A. Risk factors associated with dmft } \\
Dependent variable (dmft $=0$ Vs. dmft $\geq 1)$ \\
\hline Variables & $\mathrm{B}$ & $\mathrm{P}$ & $\mathrm{OR}(95 \% \mathrm{Cl})$ \\
\hline Age & -.467 & 0.001 & $1.62(1.83,1.54)$ \\
Gender & .168 & 0.51 & $1.18(0.70,1.97)$ \\
Annual Family income & -.209 & 0.45 & $.81(0.47,1.39)$ \\
Paternal Education & -.107 & 0.76 & $.89(0.45,1.79)$ \\
Maternal education & .236 & 0.58 & $1.27(0.54,2.95)$ \\
Frequency of cleaning teeth & -.847 & 0.095 & $.42(0.15,1.15)$ \\
Sugar consumption pattern & .98 & 0.001 & $2.68(1.58,4.53)$ \\
Utilization of dental care & 1.00 & 0.001 & $2.74(1.03,11.33)$ \\
\hline B. Risk factors associated with DMFT \\
\hline Dependent variable (DMFT $=0$ Vs DMFT $\geq 1)$ \\
\hline Variables & $\mathrm{B}$ & $\mathrm{P}$ & $\mathrm{OR}(95 \% \mathrm{Cl})$ \\
\hline Age & 1.46 & 0.001 & $4.3(2.22,8.37)$ \\
Gender & -.541 & 0.08 & $.68(0.31,1.06)$ \\
\hline Annual Family income & .173 & 0.59 & $1.18(0.63,2.24)$ \\
Paternal Education & .095 & 0.76 & $.89(0.45,1.79)$ \\
Maternal education & -1.18 & 0.08 & $.30(0.07,1.17)$ \\
Frequency of cleaning teeth & .234 & 0.67 & $.1 .26(0.42,3.75)$ \\
Sugar consumption pattern & -0.29 & 0.92 & $.97(0.52,1.80)$ \\
Utilization of dental care & .77 & 0.33 & $2.16(0.45,10.33)$ \\
\hline
\end{tabular}

Variables- Age: $\geq 5$ - 8 years and $\geq 9-12$ years, Gender: Male or Female, Annua Family Income (Rs): $\leq 60,000$ (<1000 US \$) > 60,000 ( $\geq 1000$ US \$), Paternal education: High school or lesser, Maternal education: High school or lesser, Frequency of cleaning teeth: once a day and more than once, Sugar consumption pattern (previous day): three or more times a day and less than 3 times a day, Utilization of dental care: utilized in previous one year and not utilized in previous one year.

distributive justice. Equity in health reflects an apprehension to reduce disparate opportunities to be healthy associated with affiliation in less privileged social groups, such as poor people, disenfranchised racial, ethnic, religious groups, gender, rural and slum residents [12]. In functioning terms, pursuing equity in health means eliminating health disparities that are systematically associated with underlying social disadvantage or marginalization. An equity framework systematically focuses interest on socially disadvantaged and marginalized within and between countries [13].

By 2030 all developing regions, including India will have more people living in urban than rural areas [14]. State of the World's Cities Report 20006/07 finds that the world's one billion slum dwellers specifically children are more likely to die earlier, attain less education and experience more hunger and disease than the other urban residents. The report shows remarkable similarities between slums and rural areas in health, education, employment and mortality [4].

Achieving equal opportunity for health necessitate not only safeguarding the health-damaging effects of poverty and marginalization, it also requires reducing disparities between populations in conditions such as education, living standards, and environmental exposures necessary to be healthy. Human rights and equity perspectives require health institutions to deal both with poverty and health and not in isolation. Care needs to be provided to improve the health of the poor and also to amend the circumstances that generate and perpetuate poverty and marginalization.

Majority of the slum children (> 95\%) in the present study used tooth brush and toothpaste for cleansing their teeth. Singh et al (2011) reported similar results in a study conducted in Southern India among 5 and 12- year old marginalized and disadvantaged tribal children where all used toothbrush and toothpaste for tooth cleansing $[1,3]$. On the contrary tribal children few decades back used only datum (chewing stick from tree) for cleansing their teeth [15].

Sugar consumption three or more times the previous day was noted only among $26.5 \%$ children. On the contrary, three or more times sugar consumption was noted at $40 \%$ to $100 \%$ children in National oral health survey India (2003) Southern India (2011) and Thailand (2001) $[2,10,16]$.

Only, 20 (6.4\%) 5 to 12 year old slum children had visited the dentist. Similarly, none of the tribal children aged 5 and 12 year old had visited a dentist in Southern India (2011) [1,3]. Petersen et al. in a study among 6-year-old school children in Thailand reported that as high as $66 \%$ school children had visited a dentist the previous year [16]. Badri et al (2014) conducted a systematic review to assess children's adherence to dental attendance. Factors identified at the patient level included parents' education, socioeconomic status, behavioural beliefs, perceived power and subjective norms. At the system level, collaborations between communities and health care professionals were imperative [17].

Low level of dental caries was reported despite perfunctory oral health care system with no fluoridation of water supply among the slum children. Only, 93 (26.7\%) slum children had dental caries in the primary dentition. Mean dmft scores in the primary dentition was striking low at $0.69 \pm 1.42$. Increasing age, higher frequency of previous day between meal sugar consumption and lower utilization of dental was associated with higher $\mathrm{dmft}$ scores. Similar, low prevalence and mean dmft scores of $50 \%$ and $1.94 \pm 2.81$ were reported in primary dentition among orphan children in China [18]. National oral health survey, 2003 reported dental caries among 51.9\% of the Indian 5 year old children. Higher mean dmft scores for 5- year old tribal children of $4.13 \pm 3.90$ was reported in a study conducted in southern India (2011) [1]. Similar mean dmft scores were reported from children in marginalized communities in Australia and West Indies [19,20]. Oulis et al reported $36 \%$ of 5 year old having dental caries and a mean $\mathrm{dmft}$ of 1.44 in a national pathfinder survey in Greece [21]. Higher mean $\mathrm{dmft}$ values were reported by Petersen et al in a study in Southern Thailand. At age 6, 96.3\% of children had caries and mean $\mathrm{dmft}$ of 8.1 [16]. Rajab et al (2014) reported caries prevalence of $76.4 \%$ and $\mathrm{dmft}$ o f 3.3 among 6 year old school children in Jordan [22]. Pitts et al (2007) demonstrated a wide variation in disease prevalence and care strategies across Great Britain. Mean dmft across England was 1.47, across Wales the corresponding values were 2.38 and in Scotland 2.16. Overall, 39.4\% children in Great Britain had dental caries [23]. Frazao et al (2014) reported approximately $80 \%$ children having dental caries in the primary dentition among 7-9 year old school children in Brazil and the mean $\mathrm{dmft}$ scores were $3.63 \pm 3.26$. Gender, household wealth, mother's education level, and food-insecurity was associated with dental caries [24]. Carta et al in a study conducted among 6 year old Italian school children concluded that mothers' educational level is a useful indicator for caries in Italian children living in a low-income population [25]. Present study found no association between gender, paternal and maternal education levels with $\mathrm{dmft}$ scores among the marginalized slum dwelling children.

Only, 16 (19.3\%) children had Dental Caries (DT) in the permanent dentition among the slum children. Mean DMFT score 
for the study population was again unusually low at $0.35 \pm 0.90$. Similar, low prevalence and mean DMFT scores of 39.5\%, 40\%,0.90 \pm 1.38 and 0.66 were reported in permanent teeth among orphan and rural children from low socio economic status in China (2014) and Zimbawe (2013) [18,26]. Pieper et al (2013) in National survey, Germany reported akin low caries prevalence scores of $31 \%$ and .71 mean DMFT [27]. Similarly, Zander et al reported low DMFT value of 1 among rural Australian children [28]. Rajab et al (2014) reported caries prevalence of $45.5 \%$ and DMFT of 1.1 among 12 year old school children in Jordan [22]. Higher mean DMFT scores and caries prevalence were noted in India [29], Arab league [30] and Poland [31].

Apart from the low dental caries scores an additional leading finding of the study was that only $2(.6 \%)$ among the 311 children had restoration in one or more teeth. Regardless of the low utilization of dental care, low socioeconomic status, poor literacy status of parents the disadvantaged slum children still had an extremely low level of dental caries in both primary and permanent dentition. Similar findings had been reported in many other marginalized, disadvantaged and rural communities $[1,3,18,19,20,26]$. Although, the basic diet of marginalized communities is changing yet rationale for the lower dental caries scores in these communities may be the dietary factors; specifically lower exposures to the cariogenic diet due to the lack of affordability in lower socioeconomic strata or geographic remoteness in out of reach areas.

While most public health efforts are intended to benefit the disadvantaged and vulnerable, nonetheless a deliberate approach is necessary to overcome the predisposition for the poor or marginalized to gain too little from even the best efforts [1]. Consequential participation of those who represent the poor and disadvantaged from all relevant sectors including civil society and policy makers is essential. Addressing marginalization will require a responsive and a caring workforce on the part of regional health authorities and government.

\section{Conclusion}

The present study reveals exceptionally low dental care utilization and dental caries levels among slum dwelling children. Findings from the study reflect a need to conduct further studies among slum children in to confirm the association between marginalization and low prevalence of dental caries.

\section{Acknowledgement and Competing Interest}

The study was supported by Indian Council of Medical Research (ICMR) and by Department of Dentistry, AIIMS, Bhopal - Ministry of Health \& Family Welfare, Government of India.

\section{References}

1. Singh A, Purohit B, Sequeira P, Acharya S. Oral health status of 5-year-old Aborigine children compared with similar aged marginalized group in south western India. Int Dent Journal. 2011; 61: 157-162.

2. Cruwys T, Berry H, Cassells R, Duncan A, Brien L, Sage B, et al. Marginalized Australians: Characteristics and predictors of exit over ten years. University of Canberra, Australia. 2001-2010.

3. Singh $A$, Sequiera $P$, Acharya $S$, Bhat $M$. Oral health status of two 12 yea old socially disadvantaged groups in South India: A comparative study. Oral Health Prev Dent. 2011; 9: 3-7.
4. United Nations Human Settlement Program (UN- HABITAT). The State of world's cities report. 2006/2007.

5. Report of the committee on slum statistics/census. Ministry of housing and urban poverty alleviation, National Buildings Organisation, Government of India, New Delhi. 2011.

6. Ghosh S, Shah D. Nutritional problems in urban slum children. Indian Pediatr. 2004; 41: 682-696.

7. Chen MS. Oral health of disadvantaged populations. Disease prevention and oral health promotion. Socio-dental sciences in action. Copenhagen: Munksgaard. 1995; 153-212.

8. Petersen PE. The World Oral Health Report continuous improvement of oral health in the $21^{\text {st }}$ century - the approach of the WHO Global Oral Health Programme. Community Dental Oral Epidemiol. 2003; 31: 3-24.

9. Singh A, Purohit B. Addressing oral health disparities, inequity in access and workforce issues in a developing country. Int Dent Journal. 2013; 63: 225229.

10. National oral health survey and fluoride mapping 2002-2003 India. New Delhi: Dental Council of India 2004.

11. WHO. Oral health surveys: Basic methods, Geneva: World Health Organization; 1997.

12. Braveman P, Gruskin S. Poverty, equity, human rights and health. Bulletin of the World Health Organization. 2003; 81

13. Braveman P, Tarimo E, Creese A. Equity in Health and Health Care: A WHO Initiative. Geneva: World Health Organization; 1996.

14. UN- HABITAT. Global Activities report our presence and partnerships. 2013.

15. Vaish RP. Prevalence of dental caries among tribal school children in Phulbani District, Orissa. J Indian Dent Assoc. 1983; 55: 455-457.

16. Petersen PE, Aarhus NH, Hatyai WA. Oral health status and oral health behaviour of urban and rural school children in Southern Thailand. Int Dent J. 2001; 51: 95-102.

17. Badri P, Saltaji H, Flores MC, Amin M. Factors affecting children's adherence to regular dental attendance: a systematic review. J Am Dent Assoc. 2014; 145: 817-828.

18. Gu S, Lin J, Wang M, Qian W, Wu Y, Zhu X, et al. Oral health status of 4-17-year-old orphan children and adolescents of Chongqing. 2014; 32: 378381.

19. Jamieson LM, Armfield JM, Roberts-Thomson KF. Oral health inequalities among indigenous and nonindigenous children in the Northern Territory of Australia. Community Dent Oral Epidemiol. 2006; 34: 267-276.

20. Adewakun AA. Caries status of children in Eastern Trinidad, West Indies. Oral Health Prev Dent. 2005; 3: 249-261.

21. Oulis CJ, Tsinidou K, Vadiakas G, Mamai-Homata E, Polychronopoulou A. Caries prevalence of 5, 12 and 15-year-old Greek children: a national pathfinder survey. Community Dent Health. 2012; 29: 29-32.

22. Rajab LD, Petersen PE, Baqain Z, Bakaeen G. Oral health status among 6- and 12-year-old Jordanian schoolchildren. Oral Health Prev Dent. 2014; 12: 99-107.

23. Pitts NB, Boyles J, Nugent ZJ, Thomas N, Pine CM. The dental caries experience of 5-year old children in Great Britain (2005/6). Surveys coordinated by the British Association for the study of community dentistry. Community Dent Health. 2007; 24: 59-63.

24. Frazão P, Benicio MH, Narvai PC, Cardoso MA. Food insecurity and dental caries in school children: a cross-sectional survey in the western Brazilian Amazon. Eur J Ora Sci. 2014; 122: 210-215.

25. Carta G, Cagetti MG, Sale S, Congiu G, Strohmenger L, Oleari F, et al. Oral health inequalities in Italian schoolchildren--a cross-sectional evaluation. Community Dent Health. 2014; 31: 123-128.

26. Mafuvadze BT, Mahachi L, Mafuvadze B. Dental caries and oral health practice among 12 year old school children from low socio-economic status 
background in Zimbabwe. Pan Afr Med J. 2013; 29: 144-164.

27. Pieper K, Lange J, Jablonski-Momeni A, Schulte AG. Caries prevalence in 12-year-old children from Germany: results of the 2009 national survey. Community Dent Health. 2013; 30: 138-142.

28. Zander A, Sivaneswaran S, Skinner J, Byun R, Jalaludin B. Risk factors for dental caries in small rural and regional Australian communities. Rura Remote Health. 2013; 13: 2492.

29. Mittal M, Chaudhary P, Chopra R, Khattar V. Oral health status of 5 years and
12 years old school going children in rural Gurgaon, India: an epidemiological study. Journal of Indian Soc Pedod Prev Dent. 2014; 32: 3-8.

30. Khan SQ. Dental caries in Arab League countries: a systematic review and meta-analysis. Int Dent J. 2014; 64: 173-180.

31. Rodakowska E, Wilczyńska-Borawska M, Bagińska J, Stokowska E. Epidemiological analysis of dental caries in 12-year-old children residing in urban and rural settings in the Podlaskie region of north-eastern Poland. Ann Agric Environ Med. 2013; 20: 325-328.
Austin J Public Health Epidemiol - Volume 4 Issue 1 - 2017 ISSN : 2381-9014 | www.austinpublishinggroup.com Singh et al. (C) All rights are reserved
Citation: Singh A, Raushan SK and Purohit BM. Marginalization and Its Association with Dental Caries among 5-12 Years Old Slum Children in Central India. Austin J Public Health Epidemiol. 2017; 4(1): 1053. 